\title{
A Research on Closed-Loop Control Strategy for Single-Phase Off-Grid Inverter under Abrupt Load Variation
}

$\mathrm{Na}$ Yao, Zhaoyun Zhang, Zhiping Wang

Dongguan University of Technology, Dongguan, Guangdong 523808, China. E-mail: zhangyzz@yeah.net

This paper proposes a control strategy for single-phase off-grid inverter, which integrates the three closed-loop control with the iterative-based RMS algorithm. The inverter circuit is modeled, and simulation experiment and prototype verification are performed on Matlab. The results show that the voltage drop problem caused by an abrupt variation of inverter load is improved greatly owing to the addition of voltage RMS loop. Meanwhile, the application of iterative method enhances the dynamic response performance of the system substantially; and improves the real-timeliness of three closed-loop control. The two complement each other to provide a highly effective, reliable control solution for the single-phase offgrid inverter.

Keywords: heavy load, Inverter, iterative algorithm, three-closed loop control

\section{Introduction}

Closed-loop control inverters are gaining everwider application in various power scenarios such as medical, industrial and military. The requirements for the steady-state and dynamic performances of their output voltage waveforms are becoming increasingly demanding under various load conditions. Although the conventional voltage-current double closed-loop controller is used broadly due to simple design and fast dynamic response, it can hardly achieve the zero steady-state error tracking of sinusoidal input commands in the case of abrupt load variation, which has poor steady-state accuracy. Under heavy loads, in particular, it faces a serious voltage drop problem. In this paper, we propose a three closed-loop control strategy, where the RMS sampling is achieved by adding an output voltage RMS feedback loop and by using the iterative-based fast RMS algorithm. The strategy can resolve the serious voltage drop of inverter under sudden load aggravation, and is effective in improving the system's steady-state accuracy and dynamic response speed.

\section{Inverter system model}

The inverter model adopts a single-phase fullbridge circuit structure, and its circuit topology is illustrated in Fig. 1. Where $L$ denotes the output filter inductance; $C$ denotes the output filter capacitance, and $u_{0}$ the inverter output AC voltage. The MOS drive signal is obtained by the interception of the modulated sine wave with the triangular carrier.

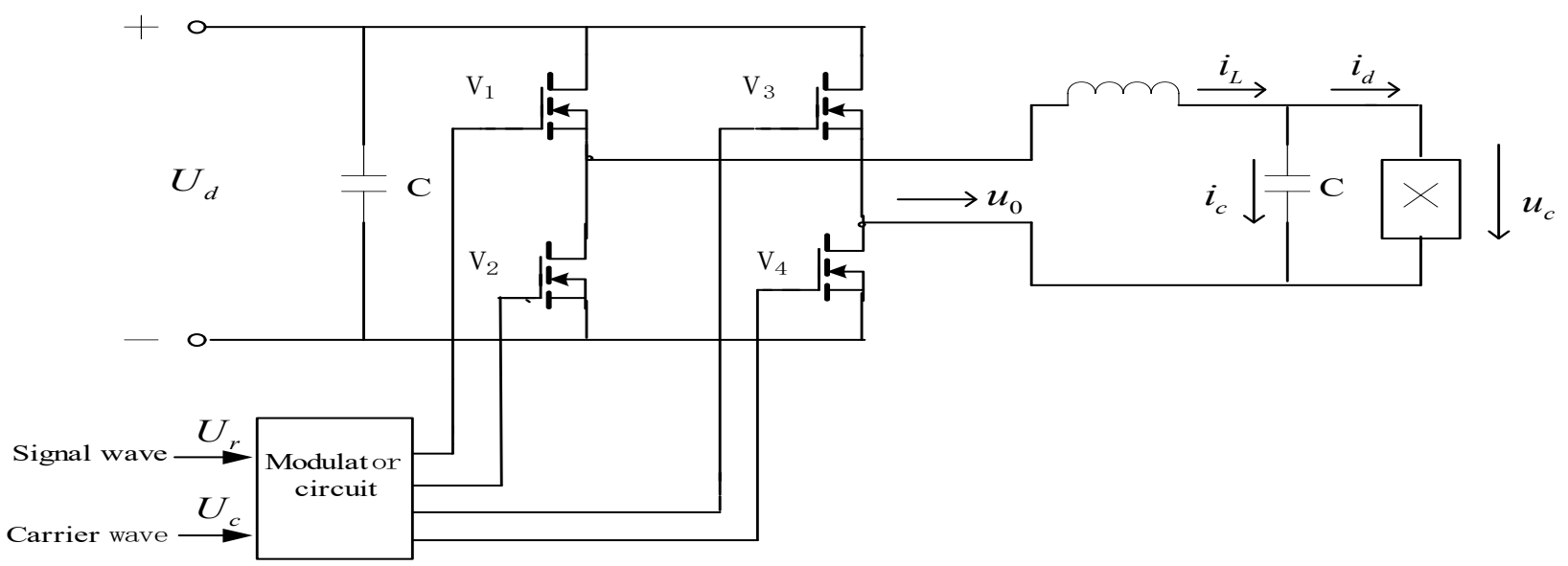

Fig. 1 Circuit topology of the single-phase full-bridge inverter 


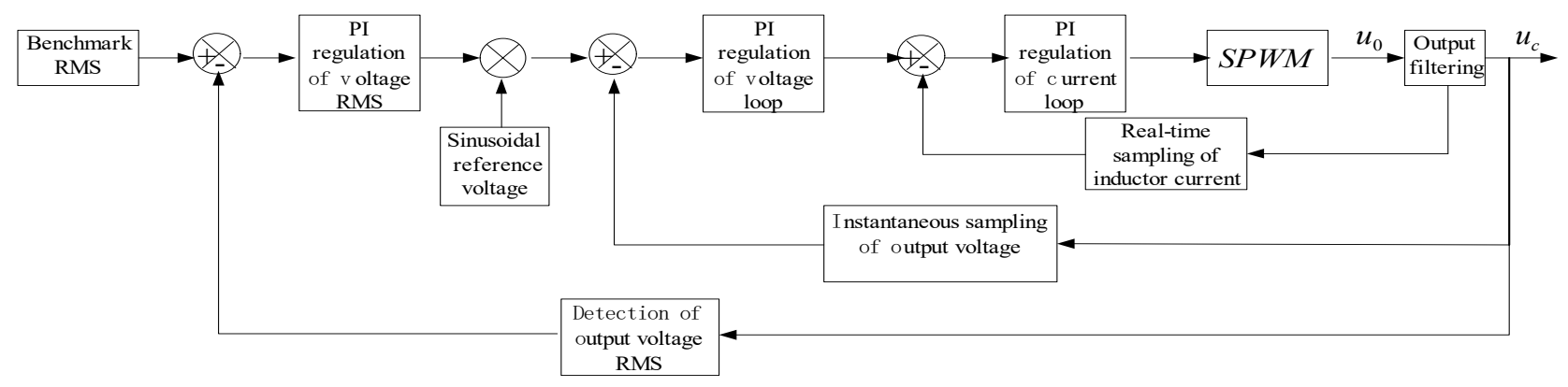

Fig. 2 Block diagram of three closed-loop control for the single-phase inverter

In Fig. 2, the block diagram of the three closedloop control for single-phase inverter is presented [1]. The inner current loop uses the sampling inductor current, so that the inductor current output can be limited within a controllable range to enhance the system reliability.

The inner voltage loop uses the instantaneous value of sampling capacitor voltage to reflect the transient variation of output voltage at any time. This allows the output voltage waveform to track the corrected reference sine wave timely to attain correction of the output voltage phase. As for the outer voltage loop, the output voltage is sampled in real time to calculate the RMS of the output voltage. This RMS value, as the feedback variable, is compared with the reference RMS, and then PI regulated. Afterwards, the resulting value is multiplied by a given sinusoidal reference voltage to yield a sine wave, which is used as a reference instantaneous value of the feedback capacitor voltage. Addition of the output voltage RMS loop allows stabilization of the output voltage near the preset reference value even in the case of abrupt load variation, so that the system's steady-state error tends to zero, thereby improving the dynamic performance of the inverter[2,3].

\section{Circuit design of inverter voltage $\&$ current output sampling hardware}

Fig. 3 displays the hardware block diagram of the full-bridge inverter system, which comprises fullbridge inverter circuit, low-pass filter circuit, sampling $\&$ signal processing circuit, drive circuit and DSP control module. The DSP adopts TMS320F28035. Featuring fast real-time processing at $60 \mathrm{Mhz}$, it enables the output module to meet the requirements through design of advanced algorithm. In Fig. 4, the circuit diagram of the minimum master control chip system is illustrated, where the current is sampled with the Hall sensor ACS712-05, and the voltage is measured through a differential circuit. After signal conditioning, the sampled data are sent to the DSP AD interface for processing and calculation to output the PWM wave. MOS turn on/off control is implemented through the drive amplifier circuit, thereby achieving $\mathrm{DC}$ to $\mathrm{AC}$ conversion. The current and voltage sampling circuits are presented in Figs. 5 and 6, respectively [4].

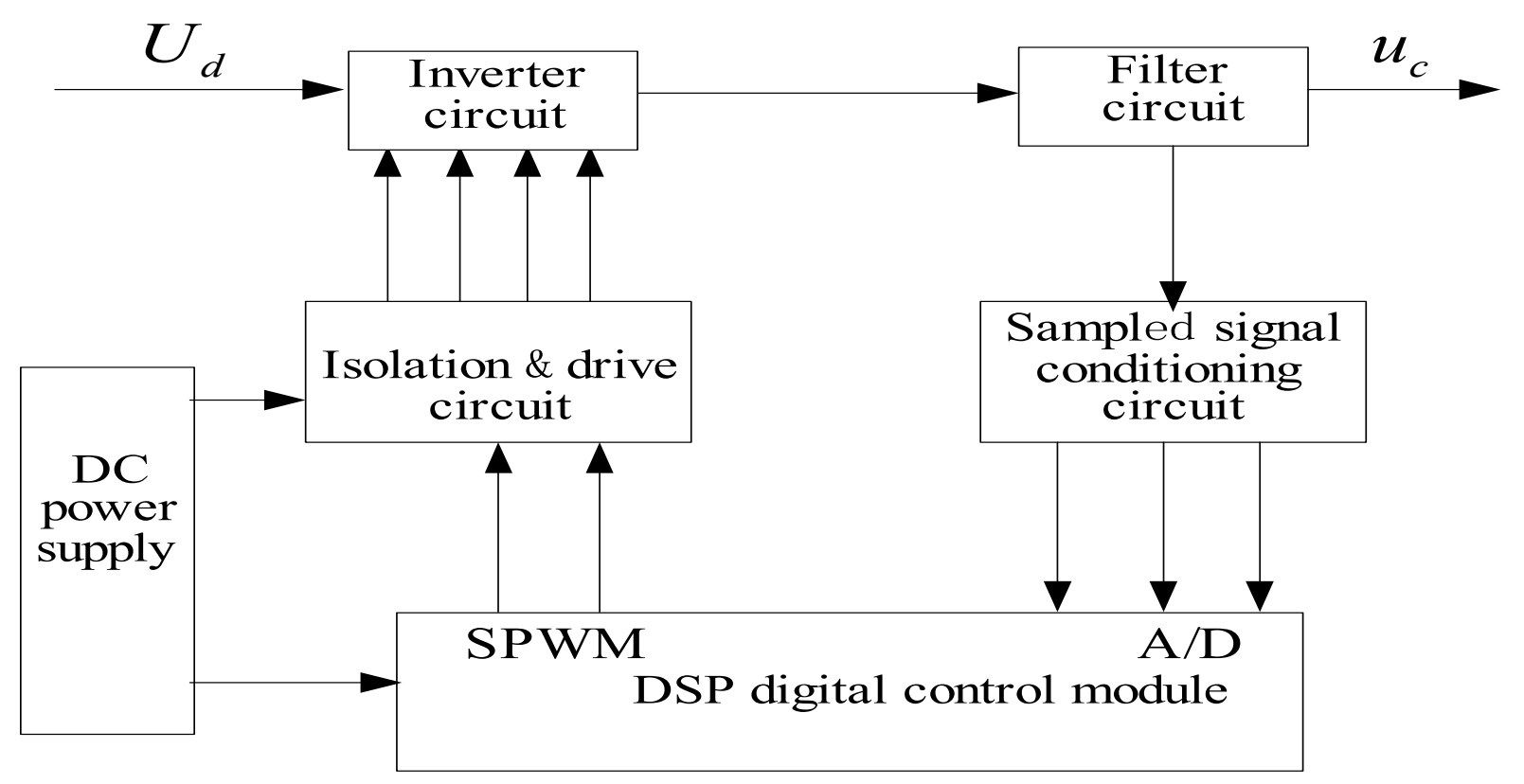

Fig. 3 Hardware block diagram of the inverter system 


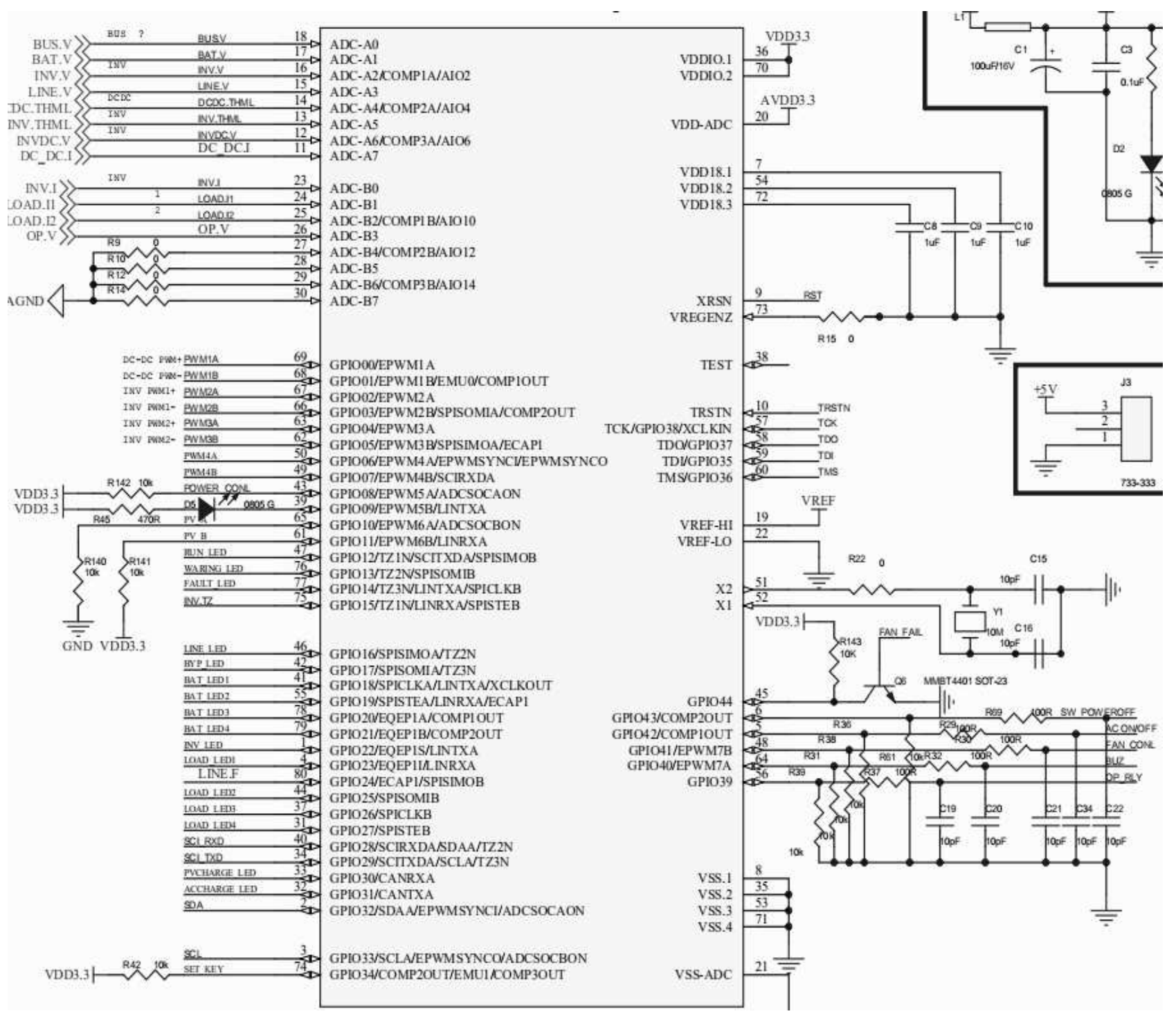

Fig. 4Minimum system schematic of TMS320F28035

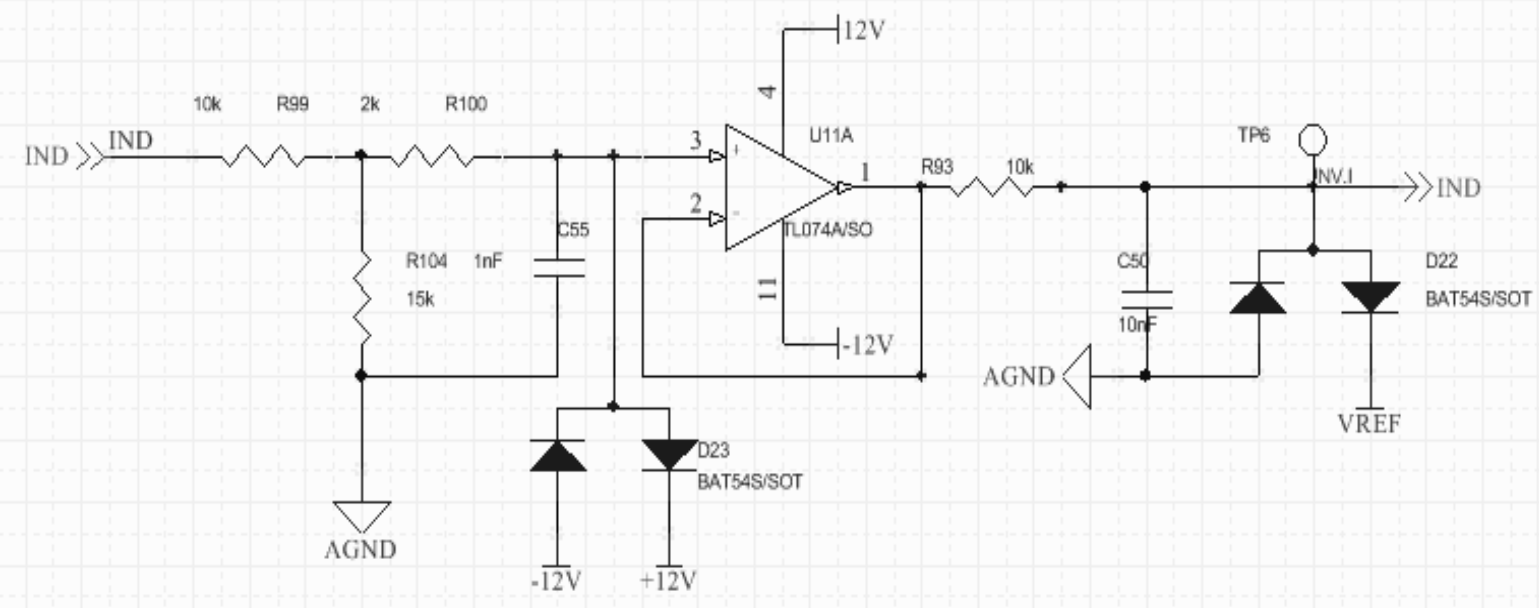

Fig. 5 Current sampling circuit diagram 


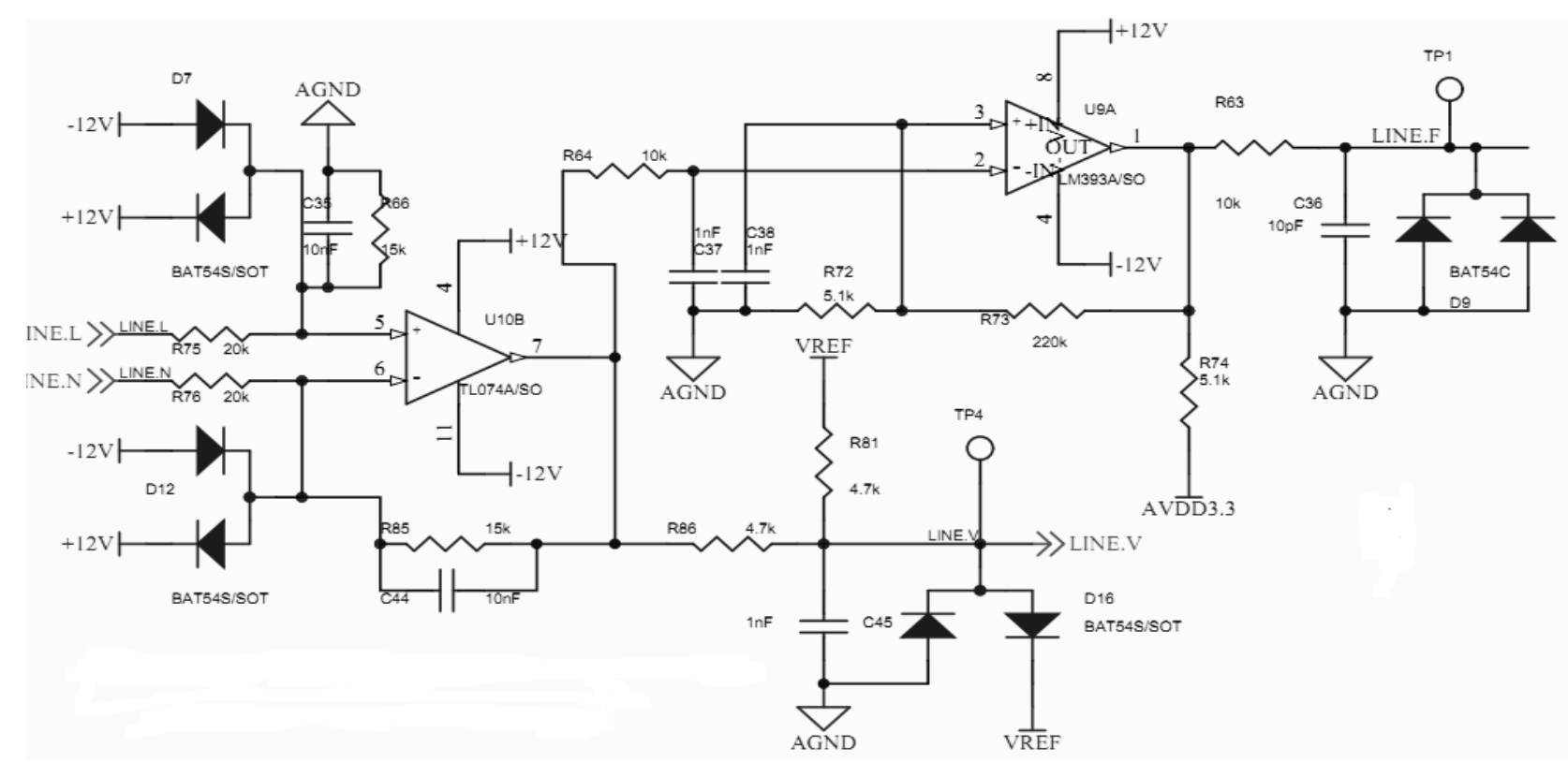

Fig. 6 Voltage sampling circuit diagram

\section{Algorithmic design of voltage RMS sampling}

Conventional method of calculating the voltage RMS is to sample ${ }^{N}$ points within a period prior to performing the RMS value operation. However, this method has poor real-timeliness since the voltage magnitudes can only be obtained after one period. As a result, the three closed-loop system has a poor dynamic performance, especially when the load changes abruptly. In this paper, an RMS algorithm based on iterative method is put forward, which can derive the RMS value of output voltage merely by sampling three points $[5,6]$.

The inverter output voltage is assumed to be a standard sine wave. $U$ is defined as the RMS of output voltage, and $f_{\text {as }}$ the output voltage frequency. The sampling interval is $\Delta T . u_{o}, u_{o+1}, u_{o+2}$ are the instantaneous values of output voltage, which are expressed separately as follows:

$$
\begin{gathered}
u_{o}=\sqrt{2} U \sin (2 \pi f n) \\
u_{o+1}=\sqrt{2} U \sin [2 \pi f(n+\Delta T)] \\
u_{o+2}=\sqrt{2} U \sin [2 \pi f(n+2 \Delta T)]
\end{gathered}
$$

The square of Eq. (2) is subtracted from the product of Eqs. (1) and (3), and then transformed through the angular function to derive:

$$
U^{2}=\frac{u_{o+1}^{2}-u_{o} u_{o+2}}{2-\cos ^{2}(2 \pi f \Delta T)}
$$

The sum of (1) and (3) is divided by (2), and then transformed to derive:

$$
\cos (2 \pi f \Delta T)=\frac{u_{o}+u_{o+2}}{2 u_{o+1}}
$$

Substituting (5) into (6) yields:

$$
U=2 \sqrt{\frac{u_{o+1}^{4}-u_{o+1}^{2} u_{o} u_{o+2}}{8 u_{o+1}^{2}-u_{o}^{2}-u_{o+2}^{2}-2 u_{o} u_{o+2}}}
$$

It can be seen from Eq. (6) that the RMS values of output voltage can be obtained simply by sampling three points. This differs from the RMS operation method, where the voltage magnitudes can only be calculated through at least $\mathrm{N}$ sampling points after one period. Thus, our method can improve the dynamic performance and real-timeliness of the three closed-loop system, especially in the case of abrupt loading or unloading [7].

\section{Control process}

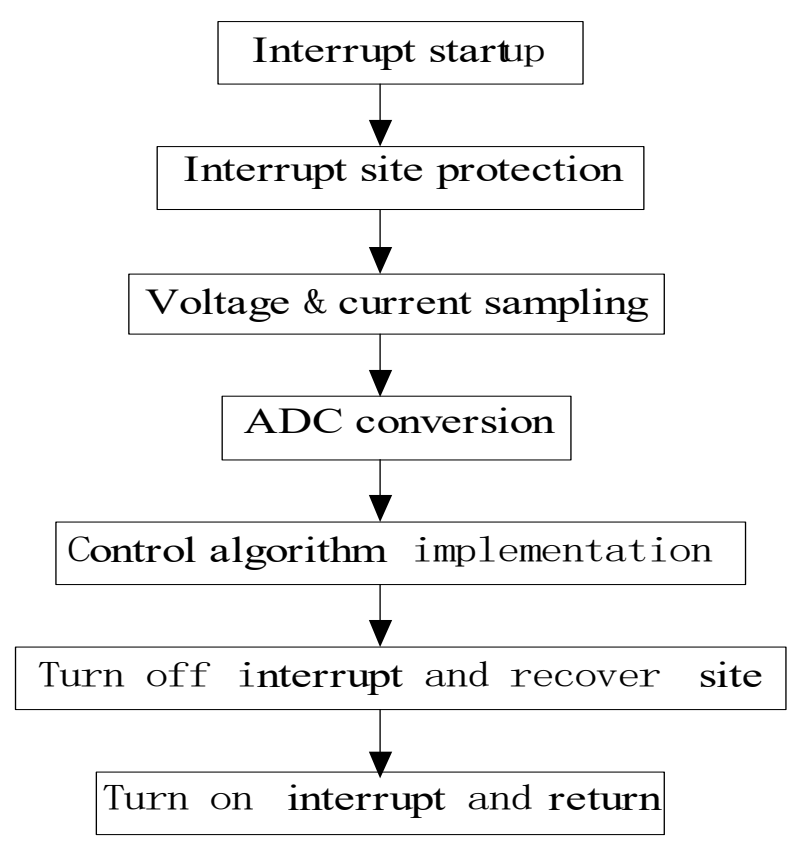

Fig. 7 Interrupt flow chart 
The inverter output voltage is sent to the AD sampling interface after sampling through the resistor divider. The RMS value of the inverter output voltage is calculated algorithmically, compared with the reference RMS, and then PI regulated to serve as the loop voltage. Its deviation from the sampling voltage is set as the current of inner current loop after passing through the voltage loop PI, which is compared with the sampling current, and then with the triangular wave to output the PWM wave[8]. The inverter control algorithm is implemented in the interrupt of the program. The flow chart is in Fig. 7.

\section{Matlab simulation and results analysis}

To verify the effectiveness of the above closedloop control strategy, a simulation model of closedloop system is built using Matlab/Simulink [9, 10], and the bipolar SPWM modulation is employed to simulate the double and triple closed-loop systems, respectively. In Fig. 8, the simulated three closed-loop system is displayed, where the switching frequency of switching tube is $20 \mathrm{KHz}$. Tab. 1 lists the relevant parameter settings.

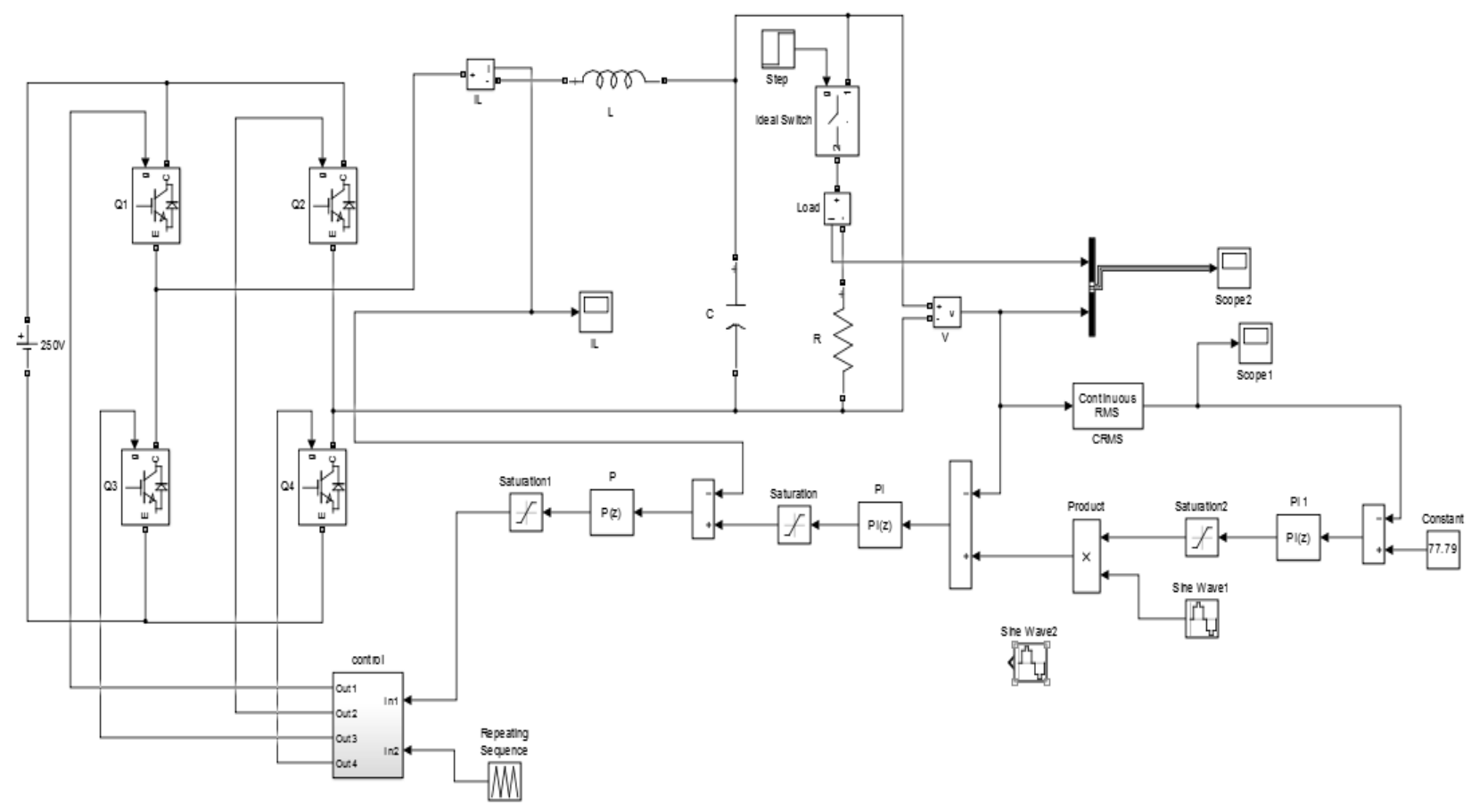

Fig. 8 Simulation chart of three closed-loop system

Tab. 1 Simulation parameter values

\begin{tabular}{ccc}
\hline Symbol & Parameter setting & Description \\
\hline$V_{i}-D C$ & $250 \mathrm{~V}$ & Input DC voltage \\
$L$ & $2 m H$ & Filter inductance \\
$C$ & $200 \mu F$ & Filter capacitance \\
$K_{i}$ & 0.1 & Integral coefficient \\
& & Of voltage instantaneous value loop \\
$K_{p 1}$ & 6 & Proportionality coefficient of voltage instantaneous \\
$K_{i 2}$ & 5.4 & value loop \\
$K_{p 2}$ & 8 & Integral coefficient of voltage RMS loop \\
$K_{p 3}$ & 20 & Proportionality coefficient of voltage RMS loop \\
& & Proportionality coefficient of current loop \\
\hline
\end{tabular}

6.1 Double closed-loop simulation under sudden heavy load

On the basis of the simulation model built in Fig. 7, the RMS loop is removed, and a $110 \mathrm{~V}$ sinusoidal reference voltage is applied to simulate the double closed-loop circuit. Fig. 9 shows the simulation waveform. Prior to $t=0.13 \mathrm{~s}$, the inverter worked in the unloaded state, with stable waveform. At $t=0.13 \mathrm{~s}$, heavy load was imposed on the inverter suddenly. At 
this point, the voltage dropped abruptly and stabilized at a new magnitude, which was unable to recover the steady state as before the sudden heavy loading. Besides, the circuit had no self-restoration capability [11].

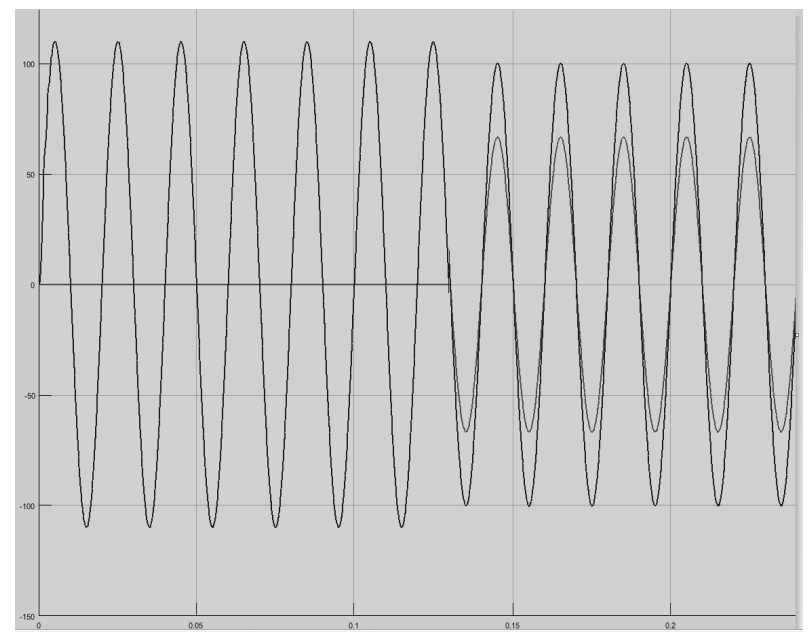

Fig. 9 Double closed-loop simulation waveform

\subsection{Three closed-loop control under sudden heavy load}

The three closed-loop circuit is simulated based on the model built in Fig. 8. Fig. 10 illustrates the simulation waveform. Prior to $t=0.13 \mathrm{~s}$, the output voltage entered a steady state after a short transient response. At $\mathrm{t}=0.13 \mathrm{~s}$, heavy load was imposed on the inverter suddenly. Afterwards, the output waveforms showed no voltage drop, which were basically consistent under heavy and empty loads. Thus, the single-phase off-grid inverter adopting the three closed-loop control strategy can address the voltage drop problem caused by abrupt load variation $[6,12]$.

Tab. 2 Results of bipolar SPWM three closed-loop modulation

\begin{tabular}{cccc}
\hline $\begin{array}{c}\text { Input voltage } \\
(\mathrm{V})\end{array}$ & $\begin{array}{c}\text { Input power } \\
(\mathrm{KW})\end{array}$ & $\begin{array}{c}\text { Output voltage } \\
(\mathrm{V})\end{array}$ & $\begin{array}{c}\text { Output power } \\
(\mathrm{KW})\end{array}$ \\
\hline 256 & 1.041 & 110.6 & 0.782 \\
250 & 1.106 & 109.5 & 1.330 \\
245 & 1.972 & 109.2 & 1.841 \\
240 & 2.654 & 108.7 & 2.490 \\
232 & 3.236 & 108.5 & 3.062
\end{tabular}

In Fig. 12, the variation trends of output voltage RMS at different output powers are presented for a zero to full-load process. The RMS of output voltage is reduced from $110.6 \mathrm{~V}$ at no load to $108.5 \mathrm{~V}$ at full load, with a load regulation of $1.89 \%$. The load regulation decreases substantially as compared to the

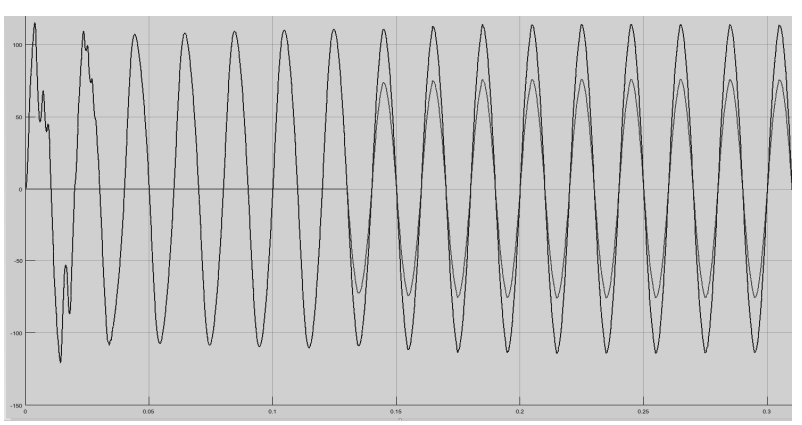

Fig. 10 Three closed-loop simulation waveform

\section{Prototype verification}

To confirm the actual effects of the theoretical algorithm and Matlab simulation, we performed three closed-loop experimental verification on a $3 \mathrm{KW}$ single-phase full-bridge inverter prototype. The prototype is shown below.

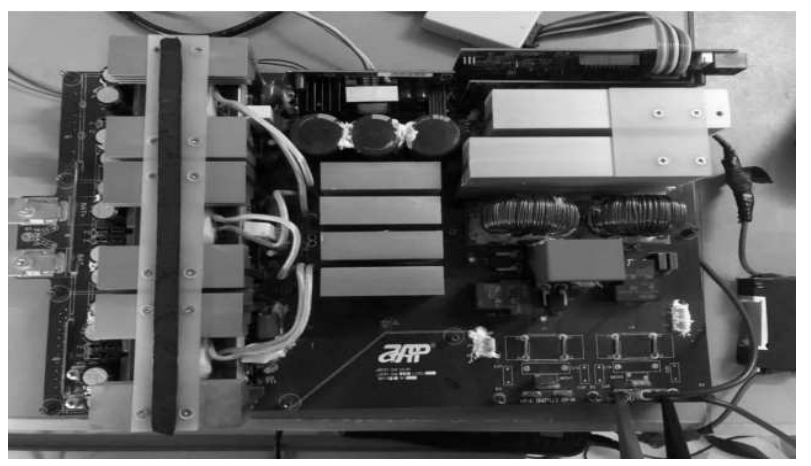

Fig. 11 single-phase full-bridge inverter prototype

The device parameters are set as follows:

Filter induktance $1.5 \mathrm{mH}$; filter capacitance 100 $\mu \mathrm{F}$; input DC voltage $250 \mathrm{~V}$; output AC voltage 110 $\mathrm{V}$; and sampling frequency $20 \mathrm{KHz}$. The bipolar SPWM modulation is adopted. Tab. 2 lists the modulation experiment results. double closed-loop scheme, and the circuit characteristics are improved greatly. The experiment proves that the dynamic performance of inverter system can be improved effectively by a control strategy comprising addition of an output voltage RMS feedback loop and a fast RMS algorithm that is based on the iterative operation. 


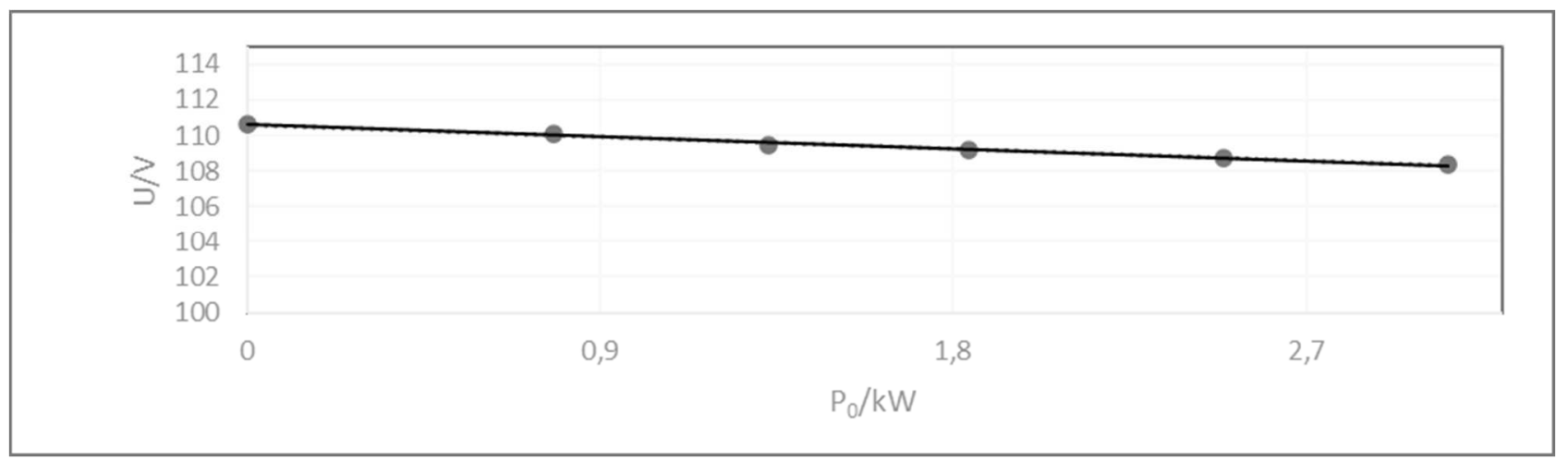

Fig. 12 Variation trends of output voltage RMS at different output powers

\section{Conclusion}

In this study, a control strategy combining the three closed-loop control with an iterative-based RMS algorithm is proposed for addressing the voltage drop and slow response problems of single-phase off-grid inverter caused by abrupt load variation under a double closed-loop control. Moreover, the strategy is verified by Matlab simulation and prototype experiment. The voltage RMS loop helps improve the voltage drop problem caused by abrupt variation of inverter load greatly, while the application of iterative method enhances the dynamic response performance of the system substantially. The experiment confirms that the whole control strategy provides an excellent control scheme for the single-phase off-grid inverter.

\section{Acknowledgement}

This study was supported by General Program of Social and Technological Development of Dongguan 2017 (program No.: 2017507140050) and Science and Technology Program of Guangdong 2017 (program No.: 2017A010104023).

\section{References}

[1] JIANG, C.F. (2015). A research on the control strategy for off-grid photovoltaic system. In: Guangzhou: South China University of Technology.

[2] ZHANG, D. (2010). Development of off-grid PV inverter and its PWM control method. In: Harbin: Harbin Institute of Technology.

[3] WANG, Y.L. (2014). Research and implementation of single-phase PV inverter control algorithm based on Matlab platform. In: Fu々hou: Fuг̨hou University.

[4] MICHAL LASKAWSKI, MIROSLAW WCISLIK. Sampling Rate Impact on the Tuning of PID Controller Parameters[J]. International Journal of Electronics and Telecommunications,2016,62(1).
[5] JIAO, D., LI, R., CAI X. (2017). A unified control strategy for on/off grid switching of singlephase inverter. In: Power Electronics, No. 5, pp. 79.

[6] QIN, B., HUANG, Y. (2015). Research on triple closed-loop control strategy of singlephase inverter under heavy load. In: The Journal of New Industrialization, Vol. 5, No. 2, pp. 33-37.

[7] ZHANG, N. (2008). Design of the $400 \mathrm{~Hz}$ three-loop three-phase inverter. In: Mechanical \& Electrical Engineering Magarine, Vol. 6, No. 6, pp. 65-66.

[8] XIONG, J., ZHOU, L. (2006). A high-precision multi-loop control strategy for singlephase PWM inverters. In: Transactions of China Electrotechnical Society, Vol. 12, No. 12, pp. 82.

[9] ZARE, M.H., MOHAMADIAN, M., BEIRANVAND, R. (2017). A single-phase grid-connected photovoltaic inverter based on a three-switch three-port flyback with series power decoupling circuit. In: IEEE Transactions on Industrial Electronics, Vol. 64, No. 3, pp. 20622071

[10] DA SILVA, C.S., MOTTA, F.R., TOFOLI, F.L. (2011). Two-stage single-phase grid-connected photovoltaic system with reduced complexity. In: International Journal of Electronics, Vol. 98, No. 6, pp. 753-767.

[11] VAN, T., NAPRSTKOVA, N. (2019). Matlabbased calculation method for partitioning a free-form surface into regions. In: Manufacturing Technology, Vol. 19, No. 3, pp. 518-524.

[12] VALČÁKOVÁ, L., ŠTEFAŇAKOVÁ, V. (2015). Test Stand Dynamics Properties Investigation by Means of Simulation Computations. In: Manufacturing Tecbnology, Vol. 15, No. 3, pp. 474-483. 